\title{
Bactérias do acido láctico e leveduras associadas com o queijo-de-minas artesanal produzido na região da Serra do Salitre, Minas Gerais
}

\author{
[Lactic acid bacteria and yeasts associated with the artisanal Minas cheese produced in the \\ region of Serra do Salitre, Minas Gerais] \\ C.D.L.C. Lima $^{1}$, L.A. Lima $^{2}$, M.M.O.P. Cerqueira ${ }^{3}$, E.G. Ferreira ${ }^{1}$, C.A. $\operatorname{Ros}^{2 *}$ \\ ${ }^{1}$ Aluna de pós-graduação - ICB-UFMG - Belo Horizonte, MG \\ ${ }^{2}$ Instituto de Ciências Biológicas - UFMG - Belo Horizonte, MG \\ ${ }^{3}$ Escola de Veterinária - UFMG - Belo Horizonte, MG
}

\section{RESUMO}

Em 10 fazendas da região da Serra do Salitre, MG, foram coletadas amostras de leite, soro fermentado (pingo), coalhada e queijo frescal para avaliar a microbiota de bactérias láticas e leveduras presentes. Uma diversidade menor de bactérias láticas foi observada durante a produção do queijo quando comparada à de leveduras. As espécies de bactérias láticas mais freqüentes foram Lactococcus lactis, Enterococcus spp., Enterococcus faecalis e Streptococcus agalactiae e de leveduras foram Debaryomyces hansenii e Kluyveromyces lactis. Apenas as populações de Enterococcus spp., Enterococcus faecalis e Leuconostoc mesenteroides apresentaram aumento significativo durante a produção do queijo. As espécies de bactérias láticas e leveduras encontradas nos diferentes substratos estudados podem ser responsáveis pelas características de aroma e sabor do queijo artesanal da Serra do Salitre.

Palavras-chave: bactérias láticas, leveduras, queijo-de-minas, Serra do Salitre

\begin{abstract}
Samples of milk, curd, cheese whey, and cheese were collected in 10 farms located at the region of Serra do Salitre, Minas Gerais state. These samples were studied in relation to their lactic acid bacteria and yeast populations. The diversity of lactic acid bacteria species was lower than the diversity of yeasts in these samples. The isolated lactic acid bacteria were Lactococcus lactis, Enterococcus spp., Enterococcus faecalis, and Streptococcus agalactiae; and the yeasts were Debaryomyces hansenii and Kluyveromyces lactis. Only the species Enterococcus spp., Enterococcus faecalis, and Leuconostoc mesenteroides showed an increase in their populations during the production of the artisanal cheese. Lactic acid bacteria and yeasts found in this study could be responsible by the sensorial characteristics of the artisanal cheese produced in the region of Serra do Salitre.
\end{abstract}

Keywords: lactic acid bacteria, yeasts, Minas cheese, Serra do Salitre

\section{INTRODUÇÃO}

O queijo-de-minas surgiu no Brasil em meados do século XVIII durante o período colonial. Os portugueses trouxeram a técnica de fabricação do queijo Serra Estrela que, mais tarde, no Brasil, foi modificada e adaptada de acordo com as

Recebido em 15 de janeiro de 2008

Aceito em 14 de novembro de 2008

* Autor para correspondência (corresponding author)

E-mail: carlrosa@icb.ufmg.br condições ambientais de cada região. Os queijosde-minas mais conhecidos são fabricados no Serro, na Serra da Canastra e na Serra do Salitre e, com o passar do tempo, conquistaram um considerável mercado consumidor (Borelli et al., 2006). Uma característica importante desses queijos é a forma artesanal de fabricação, utilizando o leite cru e o soro coletado dos 
queijos fabricados no dia anterior (chamado de pingo pelos produtores), como mostrado na Fig. 1. A microbiota nativa formada principalmente por bactérias láticas e leveduras presentes no leite e no pingo, é de grande importância para as características organolépticas do produto final.

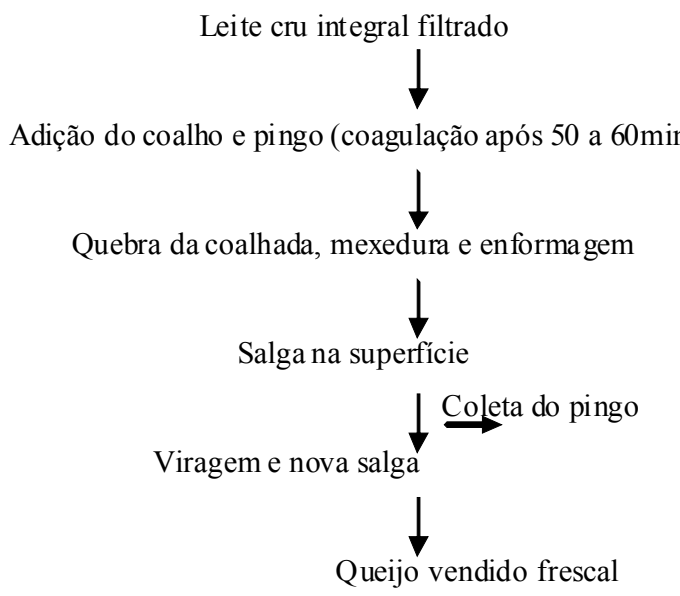

Figura 1. Fluxograma de produção do queijo-deminas artesanal da Serra do Salitre.

As bactérias láticas produzem grande número de enzimas glicolíticas, lipolíticas e proteolíticas, que transformam os nutrientes fundamentais do leite e do queijo em compostos com propriedades sensoriais desejáveis (Viljoen, 2001). Determinadas bactérias láticas utilizam, preferencialmente, a lactose como fonte de carbono, tendo como produtos de seu metabolismo diversas substâncias antimicrobianas como: ácidos orgânicos, peróxido de hidrogênio, dióxido de carbono, diacetil, acetaldeído e bacteriocinas, que atuam favoravelmente no produto alimentício ao qual foram adicionados, fazendo parte dos microrganismos capazes de exercer efeitos benéficos ao hospedeiro. São denominados microrganismos probióticos, apresentando um amplo espectro de ação contra microrganismos patogênicos e deteriorantes (Naidu e Clemens, 2000; Alexandre et al., 2002).

As leveduras têm contribuído para o desenvolvimento do sabor dos queijos por produzirem etanol, acetaldeído, etilacetato e etil butirato, resultantes da fermentação da lactose (Welthagen e Viljoen, 1999). As leveduras, pela atividade proteolítica e lipolítica, colaboram na liberação de precursores do aroma tais como aminoácidos, ácidos graxos e ésteres. Estes microrganismos também aumentam o $\mathrm{pH}$ do queijo, metabolizando o ácido lático $\mathrm{e}$ produzindo fatores de crescimento tais como vitamina B, ácido pantotênico, niacina, riboflavina e biotina (Ashenafi, 1989; Tempel e Jakobsen, 1998; Welthagen e Viljoen, 1999; Viljoen, 2001). A presença de algumas leveduras pode ser resultante de condições higiênicosanitárias inadequadas, e estas podem causar no queijo alterações organolépticas indesejáveis (Tempel e Jakobsen,1998).

Apesar de o queijo-de-minas ser um dos produtos lácteos mais apreciados no Brasil, existem poucas informações disponíveis sobre a microbiota presente nos queijos artesanais. $\mathrm{O}$ presente trabalho teve por objetivo caracterizar a microbiota de bactérias láticas e leveduras presentes no leite, no pingo, na coalhada e no queijo frescal produzido artesanalmente na região da Serra do Salitre, MG.

\section{MATERIAL E MÉTODOS}

As coletas foram realizadas em 10 fazendas, localizadas no município da Serra do Salitre, nos meses de outubro, novembro e dezembro de 2003. De cada fazenda foi coletada uma amostra de leite cru, pingo, coalhada e queijo frescal, representativas do mesmo lote de produção. No total, foram estudadas 10 amostras de leite, pingo, coalhada e queijo. Alíquotas de $25 \mathrm{~mL}$ foram retiradas do leite e do pingo e $25 \mathrm{~g}$ foram retiradas da coalhada e do queijo. As amostras de coalhada e queijo abrangiam tanto a superfície quanto a parte interna da massa. As amostras foram adicionadas em $225 \mathrm{~mL}$ de água peptonada estéril 0,1\%, homogeneizadas e diluídas. Em seguida, realizou-se a diluição decimal. Os microrganismos foram enumerados pelo plaqueamento em triplicata das alíquotas de 0,1ml de cada diluição. O ágar Man, Rogosa e Sharpe (MRS) foi utilizado para o isolamento de Lactobacillus spp. e o ágar M17 para o isolamento de Lactococcus spp. e Streptococcus spp. (Welthagen e Viljoen, 1999). As placas foram incubadas em câmara de anaerobiose ${ }^{1}$, contendo atmosfera de $\mathrm{N} 285 \%, \mathrm{H} 210 \%$ e CO 2 $5 \%$ por três dias a $37^{\circ} \mathrm{C}$. Após o crescimento, as colônias foram contadas e os diferentes

\footnotetext{
${ }^{1}$ Forma Scientific Co. Marietta, EUA.
} 
morfotipos foram estriados em ágar MRS e M17 para a obtenção de culturas puras. As bactérias foram estocadas em freezer a $-86^{\circ} \mathrm{C}$, em caldo MRS e M17 adicionado de glicerol a 20\%, para posterior identificação (Compendium..., 2001).

A identificação bioquímica foi realizada utilizando-se as seguintes análises: coloração de Gram e catalase; crescimento em caldo MRS a $10^{\circ} \mathrm{C}$ durante sete dias e a $45^{\circ} \mathrm{C} / 24 \mathrm{~h}$; fermentação de glicose em caldo MRS contendo $3 \%$ de glicose com tubos de Durhan a $37^{\circ} \mathrm{C} / 48 \mathrm{~h}$; crescimento em caldo MRS contendo 4 e $6,5 \%$ de $\mathrm{NaCl}$ a $37^{\circ} \mathrm{C} / 48 \mathrm{~h}$; crescimento em caldo de arginina a $37^{\circ} \mathrm{C} / 5$ dias, observando-se a hidrólise do aminoácido e produção de amônia, indicada pela formação de precipitado vermelho ou laranja na presença do reagente de Nessler. Placas de Elisa previamente esterilizadas foram utilizadas para verificar a assimilação dos seguintes açúcares: L-ramnose, L-sorbose, Dtrealose, D-sacarose, D-celobiose, D-melibiose, D-melizitose, D-rafinose, D-manitol, D-sorbose, salicina, D-arabinose, D-xilose, D-maltose, Dgalactose, gluconato, D-lactose, D-ribose, frutose, D-lactose, inulina. Em cada poço da placa, adicionaram-se $100 \mu \mathrm{l}$ do meio basal (caldo MRS no $\mathrm{pH} 7$ sem extrato de carne e glicose, contendo púrpura de bromocresol a $0,16 \mathrm{~g} / \mathrm{L}), 100 \mu \mathrm{L}$ do açúcar preparado e $10 \mu \mathrm{L}$ de suspensão bacteriana. As placas foram incubadas em anaerobiose a $37^{\circ} \mathrm{C}$ por $48 \mathrm{~h}$. A assimilação do açúcar foi indicada pela viragem da cor do meio de roxo para amarelo (Parente et al., 1997).

As leveduras foram enumeradas em ágar YM (extrato de malte $0,3 \%$, extrato de levedura $0,3 \%$, peptona $0,5 \%$, glicose $1 \%$, ágar $2 \%$ ), contendo $100 \mathrm{mg} / \mathrm{L}$ de cloranfenicol. As placas foram incubadas em aerobiose por cinco dias a $25^{\circ} \mathrm{C}$ (Roostita e Fleet, 1996). O número de colônias de leveduras foi contado, e os diferentes morfotipos foram purificados e estocados em freezer a $-86^{\circ} \mathrm{C}$, para posterior identificação. As leveduras foram identificadas segundo procedimento padrão (Yarrow, 1998) e chaves taxonômicas presentes em Kurtzman e Fell (1998). A diferença significativa entre a quantidade de microrganismos durante a fabricação do queijo-de-minas frescal da Serra do Salitre foi avaliada utilizando o teste de Kruskal-Wallis. O nível de significância adotado foi de $5 \%$.

\section{RESULTADOS E DISCUSSÃO}

Para cada bactéria e levedura foi aplicado o teste de Kruskal-Wallis com o objetivo de verificar se o processo de fabricação do queijo (correspondendo às amostras de leite, pingo, coalhada e queijo) apresenta contagem de microrganismos diferenciada. Assim, quando o P-valor do teste for inferior a 0,05, para aquele microrganismo as amostras têm comportamentos distintos. Durante a fabricação do queijo, ocorreu aumento significativo das bactérias láticas Enterococcus spp., Enterococcus faecalis e Leuconostoc mesenteroides com P-valor respectivos de 0,022, 0,029 e 0,031 (Tab. 1). Borelli (2002) encontrou alta contagem populacional de bactérias láticas (entre $10^{8} \mathrm{a}$ $10^{9} \mathrm{UFC} / \mathrm{g}$ ) no queijo Canastra. Freitas et al. (1995), analisando amostras de queijo Beira Baixa Picante, fabricado em Portugal, constataram, ao longo da maturação, populações de bactérias láticas de $10^{7}$ a $10^{9} \mathrm{UFC} / \mathrm{g}$. No queijo português Serra Estrela, Dahl et al. (2000) observaram que as bactérias láticas foram dominantes durante todo o período de maturação, variando de $10^{7}$ a $10^{9} \mathrm{UFC} / g$. Portanto, as contagens de bactérias láticas encontradas no presente estudo estão de acordo com aquelas obtidas nos trabalhos acima.

As espécies Lactococcus lactis, Enterococcus spp., Enterococcus faecalis e Streptococcus agalactiae foram isoladas em todas as amostras coletadas durante a fabricação do queijo. Resultados semelhantes foram encontrados por Cavalcante et al. (2003) em amostras de leite bovino usado para a fabricação de queijo de coalho da região do Vale do Jaguaribe, no Ceará. Com relação aos Enterococcus spp., apesar das limitações do uso desses microrganismos como indicadores de contaminação fecal, sua presença em número elevado nos alimentos, indica práticas sanitárias inadequadas ou exposição do alimento a condições que permitiram a multiplicação de microrganismos indesejáveis (Franco, 2003). A presença de Enterococcus faecalis e Enterococcus faecium nas amostras de queijo analisadas é um alerta para as condições higiênicas inadequadas, durante a fabricação de alguns produtos artesanais.

Lactococcus lactis tem um papel importante e desejável na fabricação de queijos pela 
fermentação de açúcares, produção de ácido lático e outros ácidos orgânicos que podem colaborar no aparecimento do sabor e aroma do produto (Tempel e Jakobsen, 1998). Leite et al. (1995), em estudos sobre culturas láticas provenientes do pingo resultante da fabricação de queijo-de-minas curado do Serro, isolaram linhagens de bactérias pertencentes aos gêneros Lactococcus spp. e Streptococcus spp. Estepar et al. (1999), ao avaliarem a microbiota lática do queijo artesanal Peñamellera, empregando testes bioquímicos semelhantes aos utilizados no presente trabalho para a identificação bacteriana, verificaram a predominância dos gêneros Lactococcus spp. e Leuconostoc spp.
Streptococcus agalactiae, encontrado durante a fabricação do queijo, é um importante patógeno causador de mastite no rebanho leiteiro, com distribuição mundial. O habitat do $S$. agalactiae é a glândula mamária de vacas, ovelhas e cabras. A infecção transmite-se pelas mãos do ordenhador, pelo equipamento de ordenha e, algumas vezes, pela boca do bezerro. No presente trabalho, apenas $40 \%$ das fazendas realizavam controle de mastite com caneca de fundo escuro, o que pode ter influenciado na alta freqüência deste microrganismo.

Tabela 1. Bactérias (log UFC/mL ou g) isoladas durante a produção do queijo-de-minas da Serra do Salitre

\begin{tabular}{lccccc}
\multicolumn{1}{c}{ Bactéria } & $\begin{array}{c}\text { Leite } \\
(\mathrm{n}=10)\end{array}$ & $\begin{array}{c}\text { Pingo } \\
(\mathrm{n}=10)\end{array}$ & $\begin{array}{c}\text { Coalhada } \\
(\mathrm{n}=10)\end{array}$ & $\begin{array}{c}\text { Queijo } \\
(\mathrm{n}=10)\end{array}$ & $\begin{array}{c}\text { P-valor } \\
\text { Kruskal- } \\
\text { Wallis }\end{array}$ \\
\hline Enterococcus spp. & 2,20 & 4,75 & 5,75 & 7,30 & 0,022 \\
E. faecalis & 2,98 & 4,94 & 5,48 & 5,40 & 0,029 \\
E. faecium & 2,00 & 4,48 & 6,09 & - & 0,189 \\
E. raffinosus & - & 4,49 & - & 4,59 & 0,114 \\
Lactococcus spp. & - & 4,45 & 5,95 & 5,0 & 0,561 \\
L.lactis & 3,63 & 4,89 & 7,18 & 6,88 & 0,051 \\
Lactobacillus & 3,0 & - & 6,41 & - & 0,392 \\
plantarum & 2,43 & - & 4,44 & 7,18 & 0,031 \\
Leuconostoc & - & - & - & 6,50 & 0,392 \\
mesenteroides & 4,20 & 5,00 & 5,34 & 6,30 & 0,261 \\
Streptococcus spp. & - & 6,75 & - & - & 0,392 \\
S. agalactiae & - & 4,32 & - & - & 0,392 \\
S.bovis & 1,97 & 4,18 & 5,71 & - & 0,061 \\
Pediococcus sp. & 1,46 & - & - & - & 0,392 \\
P. acidilati & - & 6,48 & - & - & 0,392 \\
P. dextrinicum & 2,65 & 4,98 & 5,82 & 6,14 & \\
P. pentosaceus & & & & & \\
Média & & & & & \\
\hline
\end{tabular}

Avaliando a microbiota de leveduras, verificouse que o aumento do número de microrganismos durante a fabricação do queijo não foi estatisticamente significativo, ou seja, para cada espécie, o número de microrganismos encontrados no leite, pingo, coalhada e queijo não variou significativamente. $\mathrm{O} P$-valor variou de 0,787 a 0,147 entre as leveduras estudadas. Borelli et al. (2006), ao avaliarem amostras de queijo Canastra, observaram aumento significativo das populações de leveduras em queijos com cinco dias de maturação. Welthagen e Viljoen (1999) observaram diferenças quanto ao número destes microrganismos durante o processamento do queijo Cheddar, sendo que no início do processo de fabricação, a contagem populacional foi de $10^{2} \mathrm{UFC} / \mathrm{g}$ e, no final, de $10^{7} \mathrm{UFC} / \mathrm{g}$. De acordo com esses autores, nenhuma levedura foi encontrada nos ingredientes que foram adicionados, mas, ao iniciar a fabricação do queijo, o número aumentou provavelmente devido ao contato desses ingredientes com o ar, equipamentos, roupas e com as mãos dos manipuladores. 
Apenas Debaryomyces hansenii e Kluyveromyces lactis (Tab. 2) foram isoladas em todas as amostras coletadas durante a fabricação do queijo da Serra do Salitre. Borelli et al. (2006) isolaram apenas Candida zeylanoides e Zygosaccharomyces rouxii do leite utilizado para fabricação do queijo da Serra da Canastra, número bem inferior se comparado à diversidade encontrada no leite analisado no presente trabalho. Tempel e Jacobsen (1998), ao analisarem o leite cru utilizado na fabricação do queijo dinamarquês Blue Veined, encontraram predomínio de Candida famata (estado imperfeito do D. hansenii), C. krusei, $C$. catenulata, Yarrowia lipolytica e Trichosporon cutaneum. No pingo, na coalhada e no queijo da Serra da Canastra Borelli et al. (2006) verificaram D. hansenii, Kodamaea ohmeri, Torulaspora delbruekii e $K$. lactis como as espécies predominantes. Alves (2005), ao avaliar o perfil microbiológico do queijo-de-minas frescal comercializado em Belo Horizonte, verificou que, de 278 leveduras isoladas dos queijos, $47,12 \%$ pertenciam à espécie $D$. hansenii.

Tabela 2. Leveduras ( $\log$ UFC/mL ou g) isoladas durante a produção do queijo-de-minas da Serra do Salitre

\begin{tabular}{|c|c|c|c|c|c|}
\hline Levedura & $\begin{array}{c}\text { Leite } \\
(\mathrm{n}=10)\end{array}$ & $\begin{array}{l}\text { Pingo } \\
(n=10)\end{array}$ & $\begin{array}{c}\text { Coalhada } \\
(\mathrm{n}=10)\end{array}$ & $\begin{array}{l}\text { Queijo } \\
(\mathrm{n}=10)\end{array}$ & $\begin{array}{c}\text { P-valor } \\
\text { Kruskal-Wallis }\end{array}$ \\
\hline Candida sp. & 2,10 & - & - & 5,84 & 0,124 \\
\hline C.caseinolytica & - & - & 2,45 & - & 0,392 \\
\hline C.catenulata & - & - & - & 5,46 & 0,392 \\
\hline C.catenulata similar & - & - & 2,36 & - & 0,392 \\
\hline C. azyma & 2,34 & - & - & - & 0,392 \\
\hline C.floricola-similar & - & 2,54 & - & - & 0,392 \\
\hline C.krusei & 1,34 & - & - & - & 0,392 \\
\hline C.parapsilosis & 1,34 & - & - & - & 0,392 \\
\hline C.rugosa & 1,38 & - & 3,36 & 3,04 & 0,787 \\
\hline C.rugosa-similar & - & 3,69 & - & - & 0,392 \\
\hline C.sophie-reginae & - & - & - & 3,04 & 0,392 \\
\hline C.sorbophila & - & 2,98 & 2,66 & - & 0,561 \\
\hline C.tropicalis & - & 2,67 & - & - & 0,392 \\
\hline C. stellata & - & - & - & 3,67 & 0,392 \\
\hline Cryptococcus sp. & - & 2,36 & - & - & 0,392 \\
\hline Cryptococcus hungaricus & - & 1,48 & - & 3,39 & 0,561 \\
\hline Cryptococcus flavus & 1,48 & - & - & 3,20 & 0,561 \\
\hline Cryptococcus laurentii & - & - & 2,36 & - & 0,392 \\
\hline Cryptococcus humicolus & 1,72 & - & - & - & 0,392 \\
\hline Debaryomyces hansenii & 2,59 & 5,43 & 4,51 & 6,02 & 0,169 \\
\hline Dekkera bruxelensis & - & 3,20 & - & - & 0,392 \\
\hline Kluyveromyces lactis & 2,66 & 3,82 & 4,60 & 6,05 & 0,147 \\
\hline Kodamaea ohmeri & - & 3,52 & - & - & 0,392 \\
\hline Pichia guilliermondii & 3,04 & - & 2,04 & 2,75 & 0,787 \\
\hline Pichia membranifaciens & - & 3,25 & 2,36 & - & 0,277 \\
\hline Pseudozyma antartica & 1,82 & - & - & - & 0,392 \\
\hline Rhodotorula spp. & 3,20 & 4,46 & 3,66 & - & 0,340 \\
\hline Saccharomyces sp. & - & - & 2,04 & - & 0,392 \\
\hline Saccharomyces cerevisiae & - & 3,50 & - & - & 0,392 \\
\hline Saccharomyces bayanus & - & 2,98 & - & - & 0,392 \\
\hline Saccharomycopsis fibuligera & - & 3,49 & - & - & 0,392 \\
\hline Torulaspora delbrueckii & 1,30 & 4,49 & - & - & 0,261 \\
\hline Yarrowia lipolytica & 2,04 & 3,58 & 2,36 & - & 0,787 \\
\hline Zygosaccharomyces rouxii & 2,52 & - & - & - & 0,392 \\
\hline Zygosaccharomyces sp. & - & 3,41 & - & - & 0,392 \\
\hline Média & 2,06 & 3,49 & 2,79 & 4,25 & \\
\hline
\end{tabular}


Com relação às espécies de leveduras, a alta frequência de $D$. hansenii nos queijos pode ser devida à tolerância a elevadas concentrações de sal por esta levedura, ao crescimento em baixa temperatura e a habilidade de utilizar ácido lático e cítrico como fontes de carbono (Besançon et al. 1992). Enquanto Ferreira e Viljoen (2003) sugeriram a incorporação de $D$. hansenii junto à $Y$. lipolytica na cultura iniciadora para fabricar o queijo Cheddar, Westall e Filtenborg (1998) constataram que $D$. hansenii está associado ao aparecimento de cheiro desagradável nos produtos lácteos. $Y$. lipolytica tem um papel importante na fabricação de laticínios por produzir enzimas extracelulares suficientes para modificar as características organolépticas do queijo durante a maturação (Freitas et al., 1999).

A presença frequente de $K$. lactis nos produtos lácteos analisados neste e em outros trabalhos está relacionada à sua grande habilidade de fermentar a lactose (Fadda et al., 2004). Apesar de Landell et al. (2006) verificarem o alto potencial deteriorante de $T$. delbrueckii, Westall e Filtenborg (1998) registraram que na microbiota do queijo dinamarquês Feta esta levedura foi predominante, contribuindo com o aumento do volume do queijo.

C. parapsilosis, C. tropicalis e C. krusei, consideradas patógenos oportunistas, foram isoladas em menor frequência nas amostras analisadas. A presença dessas espécies pode indicar contaminação dos substratos analisados, devido à manipulação inadequada (Álvares et al., 2007; Borelli et al., 2006). Estas espécies podem causar candidíase, também conhecida como candidose, que é uma afecção (doença) aguda, subaguda ou crônica, causada por leveduras pertencentes ao gênero Candida. Na maioria das vezes, a levedura é inofensiva no trato gastrintestinal. No entanto, eventualmente, ela pode multiplicar-se demasiadamente e ocasionar uma afecção significativa. (Aleixo Neto et al., 1999).

\section{CONCLUSÕES}

As bactérias láticas mais frequentes no presente estudo foram Lactococcus lactis, Enterococcus sp., Enterococcus faecalis e Streptococcus agalactiae. Em relação às leveduras, as espécies mais frequentes foram Debaryomyces hansenii e Kluyveromyces lactis. Apesar de verificar-se um número diversificado de espécies de bactérias láticas e leveduras, são necessários estudos aprofundados buscando avaliar a contribuição desses microrganismos nas características organolépticas do queijo artesanal produzido na região da Serra do Salitre. A caracterização das culturas lácteas presentes nos queijos fabricados de maneira artesanal pode possibilitar a seleção de culturas para iniciar o processo de fabricação desses produtos artesanais.

\section{REFERÊNCIAS BIBLIOGRÁFICAS}

ALEIXO NETO, A.; HAMDAN, J.S.; SOUZA, R.C. Prevalência de Candida na flora vaginal de mulheres atendidas num serviço de planejamento familiar. Rev. Bras. Ginec. Obst., v.21, p.441445, 1999.

ALEXANDRE, D.P.; SILVA, M.R.; SOUZA, M.R. et al. Antimicrobial activity of lactic acid bacteria from artisanal Minas cheese against indicator microorganisms. Arq. Bras. Med. Vet. Zootec., v.54, p.424-428, 2002.

ALVARES, C.A.; SVIDZINSKI, T.I.E.; CONSOLARO, M.E.L. Candidíase vulvovaginal: fatores predisponentes do hospedeiro e virulência das leveduras. J. Bras. Pat. Med. Lab., v.43, 2007.

ALVES, P.D.D. Avaliação da qualidade higiênico sanitária e determinação das espécies de leveduras presentes no queijo-de-minas frescal, produzido a partir de leite cru e leite pasteurizado, comercializado em Belo Horizonte - MG. 2005. 85f. Dissertação (Mestrado) Escola de Veterinária, Universidade Federal de Minas Gerais, Belo Horizonte.

ASHENAFI, M. Proteolytic, lipolytic and fermentative properties of yeasts isolated from ayib, a traditional Ethiopian Cottage cheese. Ethiopian J. Sci., v.12, p.131-139, 1989.

BESANÇON, X.; SMET, C.; CHABALIER, C. et al. Study of yeast flora of roquefort cheese. $J$. Food Microbiol., v.17, p.9-18, 1992.

BORELLI, B.M. Quantificação dos indicadores higiênico-sanitários e da diversidade de leveduras durante a fabricação do queijo-deminas curado produzido na Serra da Canastra, $M G$. 2002. 86f. Dissertação (Mestrado) - Escola de Veterinária, Universidade Federal de Minas Gerais, Belo Horizonte. 
BORELLI, B.M.; FERREIRA, E.G.; LACERDA, I.C.A. et al. Yeast populations associated with the artisanal cheese produced in the region of Serra da Canastra, Brazil. World J. Microbiol. Biotechnol., v.22, p.1115-1119, 2006.

CAVALCANTE， J.F.M.; ANDRADE， N.J.; FERREIRA, C.L.L.F. Isolamento de bactérias láticas de leite cru da região do vale do Jaguaribe, Ceara, Brasil. Rev. Inst. Lat. Cândido Tostes, v.58, p.106-111, 2003.

COMPENDIUM of methods for the microbiological examination of foods. 4.ed. Washington: American Public Health Association, 2001. 676p.

DAHL, S.; TAVARIA, F.K.; MALCATA, F.X. Relationships between flavor and microbilogical profiles in Serra Estrela cheese throughout ripening. Int. Dairy J., v.10, p.255-262, 2000.

ESTEPAR, J.; SANCHEZ, M.M.; ALONSO, L. et al. Biochemical and microbiological characterization of artisanal 'Peñamellera' cheese: analysis of its indigenous lactic acid bacteria. Int. Dairy J., v.9, p.737-743, 1999.

FADDA, M.E.; MOSSA, V.; PISANO, M.B. et al. Occurrence and characterization of yeast isolated from artisanal Fiore Sardo cheese. Int. J. Food Microbiol., v.95, p.51-59, 2004.

FERREIRA, A.D.; VILJOEN, C.C. Yeasts as adjunct starters in matured Cheddar cheese. $J$. Food Microbiol., v.86, p.131-140, 2003.

FREITAS, A.C.; PAIS, C.; MALCATA, F.X. et al. A microbiological characterization of picante da Beira Baixa cheese. J. Food Prot., v.59, p.155-160, 1995.

FREITAS, A.C.; PINTADO, A.E.; PINTADO, M.E. et al. Role of dominant microflora of Picante cheese on proteolysis and lipolysis. Int. Dairy J., v.9, p.593-603, 1999.

FRANCO, B.D.G.M. Microbiologia dos alimentos, 2.ed. São Paulo: Atheneu, 2003.

KURTZMAN, C.P.; FELL, J.W. The yeasts $-A$ taxonomic study. 4.ed. Amsterdam: Elsevier, 1998, 1084p.
LANDELL, M.F.; HARTFELDER, C.; VALENTE, P. Identificação e perfil enzimático de leveduras isoladas de queijo artesanal no sul do Brasil. Acta Sci. Vet., v.34, p.49-55, 2006.

LEITE, M.O; PINHEIRO, A.J.R.; CHAVES, A.H. et al. Isolamento e identificação de bactérias láticas de soro de queijo da região do Serro, Minas Gerais. In: CONGRESSO NACIONAL DE LATICÍNIOS, 13., 1995, Juiz de Fora. Anais... Juiz de Fora: Inst. Cândido Tostes, 1995. p.121-125.

NAIDU, A.S.; CLEMENS, R.A. Probiotics: natural food antimicrobial systems. Boca Raton: CRC, 2000. p.431-462.

PARENTE, E.; ROTA, M.A.; RICCIARDI, A. et al. Characterization of natural starter cultures used in the manufacture of pasta filata cheese in Basilicata (Southern Italy). Int. Dairy J., v.7, p.775-783, 1997.

ROOSTITA, R.; FLEET, G.H. The occurence and growth of yeasts in Camembert and Blueveined cheeses. Int. J. Food Microbiol., v.28, p.393-404, 1996.

SLOAN, A.E. Food industry forecast: consumer trends to 2020 and beyond. Food Technol., v.52, p.37-44, 1998.

TEMPEL, T.V.D.; JAKOBSEN, M. Yeast associated with Danablu. Int. Dairy, v.8, p.25-31, 1998.

VILJOEN, B.C. The interaction between yeasts and bacteria in dairy environments. Int. J. Microbiol., v.69, p.37-44, 2001.

WELTHAGEN, J.J.; VILJOEN, B.C. The isolation and identification of yeasts obtained during the manufacture and ripening of Cheddar cheese. Food Microbiol., v.16, p.63-73, 1999.

WESTALL, S.; FILTENBORG, O. Yeast occurrence in Danish feta cheese. Food Microbiol., v.15, p.215-222, 1998

YARROW, D. Methods for isolation, maintenance, classification and identification of yeasts. In: KURTZMAN, C.P.; FELL, J.W. The yeasts: a taxonomic study. Amsterdam: Elsevier, 1998. 